\title{
Oesophageal and gastric cancers: 8 years study inatertiary care hospital
}

\author{
Namdhari B. $\mathbf{H}^{1}$, Deshpande S. $\mathbf{A}^{2}$ \\ ${ }^{1}$ Dr. Balkrishna Harishchandrarao Namdhari, Assistant Professor, Department of Pathology, ${ }^{2}$ Dr. Shubha Arvind \\ Deshpande, Professor and Head, Department of Pathology, both authors are affiliated with Dr Shankar Rao Chavan \\ Government Medical College, Nanded, Maharashtra, India.
}

Address for Correspondence: Dr. Shubha Arvind Deshpande, 'Prayag', Plot No 223, Near Mahale Hospital, Borban, Vazirabad, Nanded, India. E-mail: shubhapath@gmail.com

\begin{abstract}
Introduction: Gastric cancers are known for male preponderance. Aims and objectives: M: F ratio of oesophageal and gastric cancers and age group differences for comparison amongst both oesophageal and gastric sites of cancers. Materials and Methods: This is a retrospective and single institute study of oesophageal and gastric cancers diagnosed duringthe tenure of last 8 years. The histopathologically confirmed diagnosis of cancers of oesophageal and gastric sites selected.Results: 28 cases of oesophageal and gastric cancers selected during the tenure of last 8 years. The oesophagus cancers are less than gastric cancers $>27 \%$ and age group for both sites are after 40 years only and more cases are seen in 40-50 age group in oesophagus and in 70-80 age groups in gastric cancers. M: F ratio for oesophagus cancers is 5.0 and for gastric cancers are 4.5.Metastatic age group is after 50 years of age in cancers of both oesophagus and gastric sites. Conclusion: Early diagnosis is the key to reduce the morbidity and mortality due to oesophageal and gastric cancers.Overall male predominance has been noted in the study. Histopathology is the most sensitive and specific diagnostic method for early detection of GI tract cancer which hasthe role in the diagnosis of gastrointestinal cancers and had aid in early management. Generation of population based data base is needed for the lesions diagnosed on gastric biopsy from different geographical regions of country. This helps in identification of spectrumof malignancies of oesophagus and stomach with early diagnosis and the improved survival of patients.
\end{abstract}

Keywords: Oesophageal cancers, Gastric cancers and stomach cancers

\section{Introduction}

Gastric canceris still the $4^{\text {th }}$ most common cancer in the world and accounts for $10 \%$ new cancer cases in the world. Approximately34000 new gastric cancer patients diagnosed in India every year. The M: F ratio of oesophageal cancers in Denmark is 5.6, Australia is 5.5, England and Wales is 5.0 and highest ratio in the world is recorded in Taiwan is 13.3 and lowest recorded in non-whites of US is 1.5 [1]. The definitive diagnosis of gastrointestinal cancers is largely depends on histopathological confirmation and is one of the bases for planning proper treatment regimen [2]. The incidence of oesophageal cancer is moderately high among the population based cancer registries the

Manuscript received: $22^{\text {nd }}$ August 2017

Reviewed: $2^{\text {nd }}$ September 2017

Author Corrected: $9^{\text {th }}$ September 2017

Accepted for Publication: $15^{\text {th }}$ September 2017 highest rate is observed in Bhopal PBCR and Chennai PBCR [3]. High incidence of oesophageal cancer in males has been reported in China (Cixians) and lowest incidence in the world has been reported in Israel (nonJews) and in India maximum cases has been reported in Aizawl district (Mizoram State) and minimum cases reported in Barshi (Maharashtra) - a PBCR covered area. And in females the maximum cases also seen in China (Cixians) and lowest incidence are seen in USA (Cali., LA, Filip.), Indian data shows maximum cases in East Khasi Hills district (MG) and lowest incidence is also seen in Barshi-PBCR covered area. High incidence of gastric cancerin males has been noted in China (Changle) and lowest incidence is also seen in BarshiPBCRcovered area in the world.Indian data shows maximum cases in Serchhipdistrict (MizoramState). 
Cancer of stomach has been a consistent leading site of cancer in males in the PBCR Chennai and PBCR Bengaluru. The relatively high incidence of gastric cancer in north eastern India is a new finding. This may relate to distinct feature of the diet such as smoked fish and meat that is consumed in these areas and is another finding that would require the specific study $[4,5$, and 6]. Worldwide gastrointestinal tract cancers stand among top 10 leading sites of cancer. Remarkable and striking differences are observed in different geographical locations and different races in the world. They remain asymptomatic for longer period and are often advanced at the time of diagnosis [7, 8]. Present study is designed to test the male preponderance of gastric cancers. Oesophageal and gastric cancers staging is at advanced state at the time of diagnosis which has reported in literature so this fact remains to be verified for that purpose a pretty long period is chosen for retrospective study.

\section{Aims and objectives}

This study is aimed to determine the M: F ratio of oesophageal and gastric cancers and the age group differences for comparison amongst the both oesophageal and gastric cancers and their trend if any. We have also tried to find out staging during the process of diagnosis.

\section{Materials and Methods}

Type of study: This is a retrospective study of available data with Pathology department.Setting: This is the single institute from where the clinical cases were chosen for the observational study. Inclusion criteria: The cases of oesophageal and gastric cancers diagnosed in the Pathology department. The cases selected for the study had confirmed histopathological diagnosis of malignancies of oesophageal and gastric cancers. Exclusion Criteria: 1) Suspicious cases are not included in this study; 2) The superficial biopsy material which does not yield the confirmative histopathological diagnosis 3) Histopathological prepared slides with artefacts during tissue processing and 4) The inadequate material in thehistopathological slides for the diagnosis were also excluded from the study. Variables: The use of clinical data regarding age, the age at which the metastasis seen and gender of the selected case is done. Data source: This data was obtained from the requisitions made by surgeons for histopathology study of the specimens submitted by them in the pathology department; the requisitions were having the data of variables required for the study.

Bias: Bias is automatically removed by using the exclusion criteria as mentioned above.Study size: All cases were screened duringthe tenure of last eight years from year 2009 to year 2016. Quantitative variables: Age at the time of diagnosis (including early diagnosis and late diagnosis in the advanced stages) and gender of the cases were quantitative variables. Statistical methods: This isbeingan observational study so the observation tables were drawn as year wise, site wise, age wise and gender wise distribution of gastrointestinal cancers.

\section{Results}

Table1 shows the part of study design where the site wise cancer cases were diagnosed in the pathology department which included the twenty eight cases of both oesophageal and gastric cancers during the tenure of last eight years from year 2009 to year 2016 were selected for analysis.

Table-1: Year wise diagnosed Cancers.

\begin{tabular}{|c|c|c|c|}
\hline Year & Oesophagus Cancers & Gastric Cancers & Total Cancers \\
\hline 2009 & 0 & 5 & 5 \\
\hline 2010 & 2 & 3 & 5 \\
\hline 2011 & 0 & 1 & 1 \\
\hline 2012 & 1 & 8 & 9 \\
\hline 2013 & 1 & 1 & 2 \\
\hline 2014 & 0 & 0 & 0 \\
\hline 2015 & 0 & 0 & 0 \\
\hline 2016 & 2 & 4 & 6 \\
\hline Total & $\mathbf{6}$ & $\mathbf{2 2}$ & $\mathbf{2 8}$ \\
\hline
\end{tabular}


Table-2: Site, age group and gender distribution.

\begin{tabular}{|c|c|c|c|c|c|c|}
\hline \multirow{2}{*}{ Age groupIn years } & \multicolumn{3}{|c|}{ Oesophagus Cancers } & \multicolumn{3}{c|}{ Stomach Cancers } \\
\cline { 2 - 7 } & Male & Female & Total & Male & Female & Total \\
\hline $40-50$ & 4 & 0 & 4 & 3 & 1 & 4 \\
\hline $50-60$ & 0 & 0 & 0 & 2 & 0 & 2 \\
\hline $60-70$ & 0 & 0 & 0 & 5 & 1 & 6 \\
\hline $70-80$ & 1 & 1 & 2 & 7 & 1 & 8 \\
\hline $80-90$ & 0 & 0 & 0 & 1 & 0 & 1 \\
\hline Missed data & 0 & 0 & 0 & 0 & 1 & 1 \\
\hline Total & 5 & 1 & 6 & 18 & 4 & 22 \\
\hline M:F ratio & \multicolumn{3}{|c|}{$\mathbf{5 : 1}$} & \multicolumn{4}{|c|}{$\mathbf{4 . 5 : 1}$} \\
\hline
\end{tabular}

Table 2 shows the site wise, age group wise and gender wise distribution of gastrointestinal cancer cases distribution. The numbers of oesophagus cancer cases were less as compared to the total number of gastric cancers. The age group for oesophageal and gastric cancer cases were commenced from 40 years of age. Oesophageal cancer cases age group remained from age 40 years to 80 year and similarly for gastric cancer cases from age of 40 years to 90 years. The quantum of more cases were seen in the age group of 40 to 50 in oesophagus cancer cases while in the gastric cancer cases the maximum cases were seen in the age group of 70 to 80 years of age. No oesophageal cancer cases seen after 80 years of age and no gastric cancer cases seen after 90 years of age. There is clear cut male preponderance in both sites of oesophageal and gastric cancers exhibiting M: F ratio for oesophagus is 5.0 and for stomach are 4.5.

Table-3: Site, age group and gender distribution of MetastaticCancers

\begin{tabular}{|c|c|c|c|c|c|c|}
\hline \multirow{2}{*}{$\begin{array}{c}\text { Age group } \\
\text { In years }\end{array}$} & \multicolumn{2}{|c|}{ Oesophagus Metastatic Malignancies } & \multicolumn{3}{|c|}{ Stomach Metastatic malignancies } \\
\cline { 2 - 7 } & Male & Female & Total & Male & Female & Total \\
\hline $40-50$ & 0 & 0 & 0 & 0 & 0 & 0 \\
\hline $50-60$ & 1 & 0 & 1 & 5 & 0 & 5 \\
\hline $60-70$ & 0 & 0 & 0 & 2 & 0 & 2 \\
\hline $70-80$ & 0 & 0 & 0 & 2 & 0 & 2 \\
\hline $80-90$ & 0 & 0 & 0 & 0 & 0 & 0 \\
\hline Missed data & 0 & 0 & 0 & 0 & 1 & 1 \\
\hline Total & $\mathbf{1}$ & $\mathbf{0}$ & $\mathbf{1}$ & $\mathbf{9}$ & $\mathbf{1}$ & $\mathbf{1 0}$ \\
\hline
\end{tabular}

Table 3 Shows the site wise, age group wise and gender wise distribution of metastatic gastrointestinal cancers distribution.In oesophageal metastatic cancer casesa single case is reported in the age group category of 50 to 60 years of age and that to male gender only. In gastric metastatic cancer cases one case is observed in female. Gastric metastatic cancers are seen in the range of 50 to 80 years of age.

\section{Discussion}

GIT cancers constitute 15 to $25 \%$ of all cancer burdens. The primary aim of the GI pathology is to provide the essential diagnostic and prognostic information, so as to enable the physicians and surgeons for the best clinical management of the patient.The incidence of oesophagealcancers has risen sharply in the western countriesover the past four decades. The M: F ratio in the prevalence of oesophageal adenocarcinoma varies depending on the country or ethnicity. Oesophageal adenocarcinoma is significantly more common in males than females irrespective of country and ethnicity. In the US, UK, Denmark and Sweden the incidence of oesophageal adenocarcinoma has been increasing in both men and women. The incidence in woman has been almost stable in the Norway and Finland. The M: F ratio in thepresentstudy of oesophageal cancers is 5.0 whichcorresponds to M: F ratio of Denmark (5.6), Australia (5.5), England and Wales (5.0) 
and the highest ratio in the world is recorded in Taiwan (13.3) and the lowest recorded in non-whites of US (1.5). Females are less affected by gastric or intestinal inflammation in response to chemical insult or bacterial infection as compared to males. This leads to differences in the incidence of gender specific carcinogenesis in females. The prevalence of oesophageal adenocarcinoma closely relates with the reproductive status of woman which reflects the level of sex hormone oestrogen. This potential effect of oestrogen could delay the development oesophageal adenocarcinoma via its anti-inflammatory function and acquisition of epithelial resistance in the oesophagus against causative refluxate which is likely responsible for the sex difference [1].

This present studyalso shows the less number of oesophageal cancer cases, and more number of gastric cancer cases, while Thakur RY et al study shows less number of gastric cancer cases and more number of oesophageal cancer cases (Fig.1).

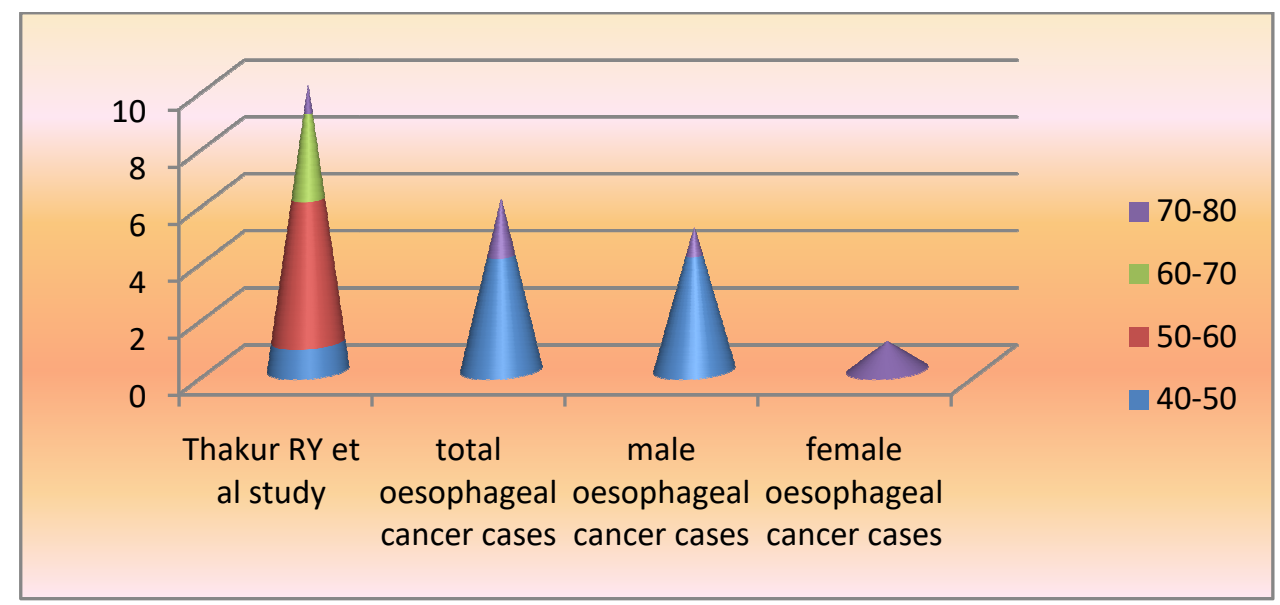

Figure-1: Cone graph of comparison of oesophageal cancer cases in present study

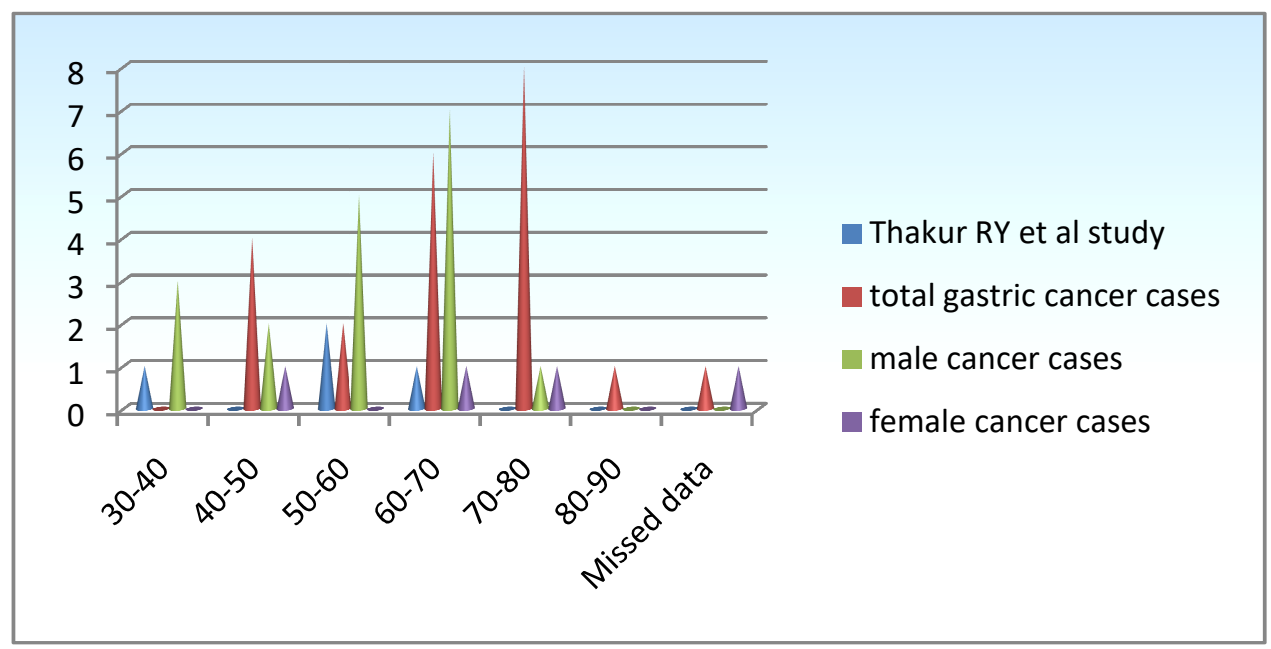

Figure-2: Cone graph of comparison age group wise, gender wise gastric cancer cases

As per Fig. 2the peak incidence of gastric cancers is in the 70 to 80 years category (36.3\%) followed by $60-70$ years category (27.2\%), while in the Study by Patne SCU et al the peak incidence is in 46-60 years of age group. The present study of gastric cancers shows M: F ratio 4.5 while in the study by Patne SCU the M: F Ratio is 2.0 (North India), west Bengal (2.7), Mizoram (2.3) and Karnataka (2.1) hence it does not corresponds to other studies. Hospital based data on gastric biopsy helps in identifying both benign and malignant lesions prevailing in the region. It gives the relative frequencies of various lesions in the stomach. There is a wide geographical variation in the incidence rate of gastric cancer within India [7]. 
Gastric cancer in the young patients below 40 years of age was studied by Seker M (Turkey study) where young patients were $57 \%$ cases were metastatic at the time of diagnosis, while gastric cancer was considered to be disease of elderly patients most commonly in $5^{\text {th }}$ and $6^{\text {th }}$ decade of life, $5-15 \%$ of patients are under 40 years of age in Turkey study and only $1-2 \%$ are under 30 years of age [8].

In this present study the incidence ofgastric metastatic cancers is at the age groups of more than 50 yearsat the time of diagnosis. This study does not match with this Turkey study, these findings are independent and cannot be compared with other studies.The lymph nodes and the liver were common targets of GI cancer metastasis.

These tumours remain asymptomatic for longer period and may present in the advanced stages of metastasis.

Present study was conducted with an aim to examine the incidence, age wise, gender wise and metastatic oesophageal and gastric cancers. Thisstudy shows the higher male preponderance showing M: F ratio 4.6:1 in combined oesophageal and gastric cancers as compared to Thakur RY et al study the M: F ratio is 2.5 in oesophageal and gastric cancers. Habitual associations were more common among the male patientswhen compared to the female patients[9].

Limitation of our study was a few missing data in medical records as with any retrospective study which we hope is not of much overall significance.

\section{Conclusion}

1. Early diagnosis is the key to reduce the morbidity and mortality due to oesophageal and gastric cancers.

2. Overall male predominance has been noted in the study.

3. Oesophageal cancer cases are maximum in the age group of 40 to 50 years and gastric cancer cases are maximum in the age group is 70 to 80 years.

4. Histopathology is regarded as the most sensitive and specific diagnostic methodfor early detection of GI tract cancerand had aid in theirearly management.

5. Generation of population based data base of lesions diagnosed on gastric biopsy from different geographical regions of our country is needed and will help in identification of spectrum of various oesophageal and gastric malignancies andearly diagnosis of malignant pathology with improved survival of patients.

Funding: Nil, Conflict of interest: None initiated, Permission from IRB: Yes

\section{References}

1.Asanuma K, Iijima K, Shimosegava T. Gender difference in gastro-oesophageal reflux diseases.World J Gastroenterol2016;22(5):1800-1810 Available from: URL: http://www.wjgnet.com/1007-9327/full/v22/i5/ 1800.htmDOI:http://dx.doi.org/10.3748/wjg.v22.i5. 1800.
2. Das C, Maity N, Mukhopadhyay M, Mukhopadhyay B, Basu K, Madhukumari. A histopathological spectrum of gastrointestinal tract lesions in a tertiary care hospital: An epidemiological study for four years. IOSR - JDMS. Feb 2016, 15(2) Ver II; 74-77. Available fromhttp: //iosrjournals. org/iosr-jdms/papers/Vol15issue 2 /Version-2/O01527477.pdfDOI: 10.9790/08531527477

3. Nandkumar AK, Dhār M. NCRP, Five years consolidated report of hospital based cancer registries 1994-1998, An assessment of the burden and care of cancer patients.New Delhi,ICMR,November2002.112p.

4. Nandkumar AK, Gupta PC, Gangadharan P, Visweswara RN, Parkin DM. Geographic pathology revisited: development of an atlas of cancer in India. Int J Cancer. 2005 Sep 20; 116 (5): 740-54.Available from http://onlinelibrary.wiley.com/doi/10.1002/ijc.21109/ful IDOI: 10. 1002/ ijc.21109.

5. Nandkumar AK, Gupta PC, Gangadharan, Visweswara RN. Development of an atlas of cancer in India, A project of the national cancer registry programme (Indian council of medical research) supported by World Health Organization, First all India report: 2001-2002 Mapping patterns of cancer, Information technology in medicine- Measuring burden of disease, Volume I, Bengaluru, India: National Cancer Registry Programme (ICMR); April 2004. 271p - 438p. 
6. Nandkumar AK, Gupta PC, Gangadharan, Visweswara RN. Development of an atlas of cancer in India, A project of the national cancer registry programme (Indian council of medical research) supported by World Health Organization, First all India report: 2001-2002 Mapping patterns of cancer, Information technology in medicine-Measuring burden of disease, Volume II, Bengaluru, India: National Cancer Registry Programme(ICMR);April2004. 270p

7. Patne SCU, Kumar S, Ghosh KA, Katiyar R, Srivastav RK, Das M, Pandey P, Dixit VK. A Study on differential histopathological diagnosis of gastric biopsy from a tertiary care centre. Indian J Prev Soc Med, 47 (1-2), 2016, 30-35.Available from https://www. researchgate. net/ publication/ 313026890
8. Seker M, Aksoy S, Ozdemir NY, Uncu D, Zengin N. Clinicopathological features of gastric cancer in young patients. Saudi J Gastroenterol 2013; 19 (6): 258-61 Available from: http://www. saudijgastro.com/ text. asp? 2013/19/6/258/ 120876 DOI: 10.4103/1319-3767. 120876

9. Thakur RY, Nikumbh DB, Swami SY. Clinicohistopathological overview of GIT lesions in a rural hospital: Indian J Pathol Oncol, April-june2016; 3(2); 305-314.Available from http://oaji.net/artcles/ 2016 / 1770-1467607386.pdfDOI:10.5958/2394-6792. 2016. 00058.2 .

\section{How to cite this article?}

Namdhari B. H, Deshpande S. A. Oesophageal and gastric cancers: 8 years study inatertiary care hospital. Trop J Path Micro 2017;3(3):329-334.doi: 10.17511/jopm.2017.i3.18. 